\title{
Preparation and Characterization of Nanoporous Sodium Carboxymethyl Cellulose Hydrogel Beads
}

\author{
Gulen Oytun Akalin (iD) ${ }^{1}$ and Mehlika Pulat ${ }^{2}$ \\ ${ }^{1}$ Scientific and Technological Application and Research Center, Aksaray University, 68000 Aksaray, Turkey \\ ${ }^{2}$ Chemistry Department, Gazi University, Beşevler, 06500 Ankara, Turkey \\ Correspondence should be addressed to Gulen Oytun Akalin; gulenoytunakalin@hotmail.com
}

Received 9 November 2017; Revised 20 February 2018; Accepted 26 February 2018; Published 15 April 2018

Academic Editor: Renyun Zhang

Copyright ( 2018 Gulen Oytun Akalin and Mehlika Pulat. This is an open access article distributed under the Creative Commons Attribution License, which permits unrestricted use, distribution, and reproduction in any medium, provided the original work is properly cited.

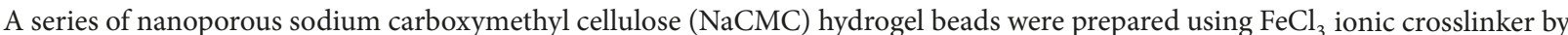
changing polymer and crosslinker percentages (\%). Characteristics of the hydrogels were investigated by gel content, swelling test, degradation test, Attenuated Total Reflectance-Fourier Transform Infrared (ATR-FTIR), Scanning Electron Microscope/Energy Dispersive X-ray Analysis (SEM/EDX), and Atomic Force Microscopy (AFM). Swelling experiments were studied by changing time, temperature, and $\mathrm{pH}$. The swelling percentage $(S \%)$ regularly decreased with increasing the amounts of polymer and crosslinker, in contrast with gel content results. $\mathrm{NaCMC}$ hydrogels were found to be sensitive to $\mathrm{pH}$ variations. The degradation test showed that hydrogels had good stability and their degradation period varied from 30 to 36 days. According to SEM analysis, NaCMC hydrogels had mostly nanoporous structure. The average granule and pore sizes of the least swollen NaCMC-12 hydrogel were found to be $13.1 \pm 0.3 \mathrm{~nm}$ and $82.1 \pm 3.2 \mathrm{~nm}$. The elemental compositions of hydrogels were determined with EDX. The minimum average surface roughness $\left(R_{\mathrm{a}}\right)$ and root mean square roughness $\left(R_{\mathrm{ms}}\right)$ parameters were found to be $15.7 \pm 1.9 \mathrm{~nm}$ and $20.3 \pm 2.2 \mathrm{~nm}$ for NaCMC-12 hydrogels by AFM. Due to their good morphologies, stabilities, and swelling behaviors, NaCMC hydrogels can be suitable for biomaterial applications.
\end{abstract}

\section{Introduction}

Hydrogels are hydrophilic polymeric materials having threedimensional network structures and can swell considerably in aqueous medium without being dissolved [1]. Their affinity to absorb water is attributed to existence of chemical groups such as carboxylic acid, amine, hydroxyl, amide, and sulfonic acid groups [2]. They have been extensively studied and used for many applications in medicine, such as controlled drug release matrices [3-5], enzyme and yeast cell immobilizations $[6,7]$, and agriculture $[8,9]$. The water content in the equilibrium of swelling affects different properties of the hydrogels: permeability, mechanical properties, surface properties, and biocompatibility [10].

The creation of interconnected porosity networks within polymeric hydrogels may improve their diffusion performance. Arranging porous structure of polymeric matrix may allow the selective solvent/solute permeability [11]. Besides, the swelling capability of porous hydrogel is significantly affected by the topological features of the porous network, mainly the void fraction and the pore size and interconnectivity. Furthermore, the pore structure features of the hydrogels, especially in terms of the porosity, pore architecture, and pore size distribution, are strongly needed for allowing the threedimensional cell and tissue infiltration in tissue engineering applications [12].

Nanoporous materials are also of scientific and technological importance because of their vast ability to adsorb/ absorb and interact with atoms, ions, and molecules on their large interior surfaces and in the nanometer-sized pore space. They offer new opportunities in areas of inclusion chemistry, host-guest synthesis and molecular manipulations, and reaction in the nanoscale for making nanoparticles, nanowires, and other quantum nanostructures [13].

Sodium carboxymethyl cellulose ( $\mathrm{NaCMC}$ ) is a representative cellulose derivative, which is water soluble cellulose 
ether, manufactured by reacting sodium monochloroacetate with cellulose in alkaline medium. $\mathrm{NaCMC}$ is a polysaccharide polymer with excellent bioadhesive properties, biodegradability, and biocompatibility.

It is also known that $\mathrm{NaCMC}$ is a polyelectrolyte, and thus this "smart" cellulose derivative presents sensitivity to $\mathrm{pH}$ and ionic strength variations. It is easy to form $\mathrm{NaCMC}$ hydrogels because of the large number of reactive hydroxyl groups on the polymer chains. Besides, the presence of carboxylate groups in the macromolecular chain enables bonding the chains to each other via multivalent ionic crosslinking. Several kinds of ions can be used to form ionic hydrogels. As an ecofriendly and nontoxic crosslinking agent, trivalent iron $(\mathrm{Fe} 3+)$ is a suitable ion to prepare NaCMC hydrogels $[14,15]$. Indeed, the presence of NaCMC in a cellulose-based hydrogel enhances electrostatic charges in network, which have a double effect on the swelling capability. $\mathrm{NaCMC}$ is widely used in several applications such as cosmetics, food and wound care industries, medicine, and agriculture for gelling, thickening agent, stabilizer, and suspending agent [16-18].

The aim of this study was to prepare a series of $\mathrm{NaCMC}$ hydrogel beads in nanoporous structure via ionic crosslinking method using $\mathrm{FeCl}_{3}$. The swelling, gel content, and degradation test were also studied to determine the optimum preparation conditions of $\mathrm{NaCMC}$ hydrogels. Additionally, the chemical structures, surface morphologies, elemental compositions, and surface roughness parameters of hydrogels were investigated by Attenuated Total Reflectance-Fourier Transform Infrared (ATR-FTIR), Scanning Electron Microscope/Energy Dispersive X-ray Analysis (SEM/EDX), and Atomic Force Microscopy (AFM).

\section{Materials and Methods}

2.1. Materials. NaCMC (average degree of substitution 0.70 and nominal Mw $250 \mathrm{~kg} / \mathrm{mol}$ ) and Iron(III) chloride hexahydrate (98\%) were purchased from Sigma-Aldrich. BrittonRobinson buffer (BRB) solution was prepared as given in the literature [19]. It consists of a mixture of $0.04 \mathrm{M}$ boric acid (Merck), 0.04 M phosphoric acid (Riedel-de Haën), and $0.04 \mathrm{M}$ acetic acid (Sigma-Aldrich), which has been titrated to the desired $\mathrm{pH}$ with $0.2 \mathrm{M}$ sodium hydroxide (SigmaAldrich).

2.2. Preparation of NaCMC Hydrogel Beads. 12 types of NaCMC hydrogel beads were prepared via ionic crosslinking reaction using $\mathrm{FeCl}_{3}$ as a crosslinker. The amounts of components used to form hydrogels are given in Table 1. NaCMC powder was dissolved in distilled water, and it was homogenously mixed with a mechanical stirrer $(200 \mathrm{rpm})$ for $24 \mathrm{~h}$. NaCMC solution was dropwise added continuously into $25.0 \mathrm{~mL} \mathrm{FeCl}_{3}$ solution by using a 26-gauge needle. The obtained spherical hydrogel beads were mixed with a mechanical stirrer $(200 \mathrm{rpm})$ for $3 \mathrm{~h}$. They were filtered and washed several times with distilled water to remove unreacted $\mathrm{FeCl}_{3}$ on the surface of beads and dried under room temperature for $24 \mathrm{~h}$ [20].
TABLE 1: The amounts of the components used to form hydrogels and gel content (\%).

\begin{tabular}{lccc}
\hline Hydrogel & NaCMC (\%) & $\mathrm{FeCl}_{3}(\%)$ & Gel content $(\%)$ \\
\hline NaCMC-1 & 3 & 4 & $74.2 \pm 0.3$ \\
NaCMC-2 & 3 & 6 & $78.3 \pm 0.4$ \\
NaCMC-3 & 3 & 8 & $80.4 \pm 0.9$ \\
NaCMC-4 & 3 & 10 & $85.6 \pm 0.8$ \\
NaCMC-5 & 5 & 4 & $90.1 \pm 1.1$ \\
NaCMC-6 & 5 & 6 & $90.8 \pm 1.2$ \\
NaCMC-7 & 5 & 8 & $91.9 \pm 0.9$ \\
NaCMC-8 & 5 & 10 & $94.5 \pm 1.3$ \\
NaCMC-9 & 7 & 4 & $94.8 \pm 1.2$ \\
NaCMC-10 & 7 & 6 & $96.2 \pm 1.1$ \\
NaCMC-11 & 7 & 8 & $97.4 \pm 1.1$ \\
NaCMC-12 & 7 & 10 & $98.9 \pm 0.9$ \\
\hline
\end{tabular}

2.3. ATR-FTIR Analysis. The chemical structures of NaCMC polymer and hydrogel were characterized by ATR-FTIR. The measurements were performed using a Bruker Vertex 70 Infrared Spectrometer equipped with diamond. The measurements were recorded in transmission mode with an incident beam angle of $65^{\circ}$, using p-polarized radiation (ZnSe wire grid polarizer). The ATR-FTIR spectra were obtained in the spectral region of $400-4000 \mathrm{~cm}^{-1}$, using a resolution of $4 \mathrm{~cm}^{-1}$ and 25 scans.

2.4. Gel Content (\%). The gel content, expressed as the fraction of insoluble weight, was obtained by extracting the soluble part in boiling water for $24 \mathrm{~h}$ using soxhlet apparatus and drying the insoluble part completely in a vacuum oven at $50^{\circ} \mathrm{C}$. Gel content (\%) was determined gravimetrically from $[17,21,22]$.

$$
\text { Gel content }(\%)=\frac{W_{1}}{W_{0}} \times 100,
$$

where $W_{0}$ is the initial weight of dried samples before extraction (total of soluble weight and insoluble weight) and $W_{1}$ is final weight (weight of insoluble part of hydrogels after extraction). This experiment was carried out in triplicate.

2.5. Swelling Behaviors. Swelling tests of hydrogel beads were gravimetrically carried out in three steps. In the first step, the weighed dried hydrogels were immersed in $100 \mathrm{~mL}$ of swelling medium $\mathrm{BRB}$ solutions at $\mathrm{pH}=7.0,30^{\circ} \mathrm{C}$. Swollen gels removed from the swelling medium at regular intervals. Then, they were dried superficially with a filter paper, weighed, and placed into the same bath. The tests were performed until constant weight was reached. The swelling percentages (S\%) of hydrogels were calculated from [23-25].

$$
S \%=\frac{\left(W_{2}-W_{1}\right)}{W_{1}} \times 100,
$$

where $W_{1}$ is the dry weight of the sample before swelling and $W_{2}$ is the swollen mass of sample in every $24 \mathrm{~h}$. 
In the second step, the dried hydrogels were swollen in $\mathrm{BRB}$ solution $(\mathrm{pH}=7.0)$ at different temperatures ranging from 10 to $60^{\circ} \mathrm{C}$ to determine the effect of temperature on swelling behaviors. In the third step, dried hydrogels were immersed in different BRB solutions at various $\mathrm{pH}$ values (from 2.0 to 12.0 ) to investigate the effect of $\mathrm{pH}$ on the swelling behaviors. At the end of $24 \mathrm{~h}$ incubation, the swollen hydrogels were taken out from swelling medium, dried, and weighed. The reproducible results for all swelling studies were obtained with triplicate measurements.

2.6. Degradation Test. Degradation tests of hydrogel beads were performed at $\mathrm{pH}=7.0,30^{\circ} \mathrm{C}$. Dried samples were left to swell in BRB. At the end of $24 \mathrm{~h}$, swollen gels were removed from solution and weighed. This mass $\left(W_{m}\right)$ was recorded as the maximum swollen state of hydrogels. Then, they were placed into the same medium and the weighing was continued at regular intervals until hydrogel completely degraded. The degradation was determined in terms of weight loss (\%) from $[26,27]$.

$$
\text { Weight loss }(\%)=\frac{\left(W_{m}-W_{t}\right)}{W_{m}} \times 100,
$$

where $W_{m}$ is the weight of hydrogel at most swollen stage and $W_{t}$ is the weight of hydrogel at time $t$. All measurements were performed in triplicate.

2.7. SEM/EDX Studies. In order to investigate the effect of polymer and crosslinker concentration on surface morphology, NaCMC-1, NaCMC-4, NaCMC-5, NaCMC-8, NaCMC9, and NaCMC-12 hydrogels were selected for SEM analysis. Surface and cross-section morphologies of these hydrogels were investigated. For this purpose, the hydrogel samples were rapidly frozen at $-80^{\circ} \mathrm{C}$ and then dried in a Labconco FreeZone 4.5 Freeze Dryer. Dried and swollen samples were mounted by double-sided tape on SEM stubs and coated with gold in a Polaron SC 502 Sputter Coater. Then the samples were examined with Fei Quanta 250 SEM at accelerating voltage $5 \mathrm{kV}$ and photos were taken.

To confirm the presence of $\mathrm{FeCl}_{3}$ in hydrogels, EDX analysis was also carried out. For this analysis, NaCMC5, NaCMC-6, NaCMC-7, and NaCMC-8 hydrogels were chosen, and their elemental compositions were determined with EDX [28].

2.8. AFM Studies. AFM analysis was studied to determine the surface topology of hydrogel beads. The effect of polymer and crosslinker concentrations on surface roughness parameters was evaluated. AFM analysis was performed by using an AFM Plus+ Model Microscope, NanoMagnetics Instruments. Topographic images were taken in tapping mode in air and collected with a scan size of $10 \times 10 \mu \mathrm{m}$ and a frequency of $0.5 \mathrm{~Hz}$. Average surface roughness $\left(R_{\mathrm{a}}\right)$ and root mean square roughness $\left(R_{\mathrm{ms}}\right)$ were obtained from the roughness analysis facility of NanoMagnetics software. $R_{\mathrm{a}}$ represents the mean vertical deviation of surface, peaks, and valleys from a mean height. $R_{\mathrm{ms}}$ is the standard deviation in height values
( $Z$ values) [29]. All roughness parameters were expressed in nanometers.

\section{Results and Discussion}

3.1. ATR-FTIR Analysis. According to the literature, the general mechanism shown in Figure 1 can be suggested for ionic crosslinking between carboxylic groups of polymer and crosslinker [20].

The spectra of NaCMC polymer and hydrogel are presented in Figure 2. Two strong peaks appeared at 1619 and $1420 \mathrm{~cm}^{-1}$ due to asymmetric and symmetrical $-\mathrm{COO}^{-}$ groups in polymer. The absorption bands appearing at $1014 \mathrm{~cm}^{-1}$ and $2920 \mathrm{~cm}^{-1}$ belonged to $\mathrm{C}-\mathrm{O}$ and aliphatic $\mathrm{C}-\mathrm{H}$ stretching vibrations. The bands in the region of $1400-1500 \mathrm{~cm}^{-1}$ and $3500-3000 \mathrm{~cm}^{-1}$ represented $-\mathrm{CH}_{2}$ stretching vibrations and $-\mathrm{OH}$ groups of polymer and hydrogel, respectively. The lower wavelength in hydrogel demonstrated the presence of the intermolecular hydrogen bonding. It was estimated that the extra peak at $1751 \mathrm{~cm}^{-1}$ in hydrogel spectra was due to the electrostatic interaction between carboxylic groups of polymer and $\mathrm{Fe}^{3+}[30,31]$.

3.2. Gel Content (\%). The gel contents of NaCMC hydrogel beads are given in Table 1 . The lowest gel content was found to be $74 \%$ for NaCMC-1 hydrogel. When the concentration of NaCMC was increased from $\% 3$ to $\% 7$, also the gel content of the samples increased. The highest gel content was found to be $99 \%$ for NaCMC-12 hydrogel. The higher density improved the network binding forces of the polymers, which led to the increase of gel content. It is well known that polymer and crosslinker amounts promote the gel content, so the results are consistent with literature $[14,22]$.

3.3. Swelling Behaviors. The variations of $S \%$ values with time at $\mathrm{pH} 7.0$ and $30^{\circ} \mathrm{C}$ are shown in Figure 3(a). As can be seen from this figure, initially $S \%$ increased with time and then remained stable at nearly $24 \mathrm{~h}$. $S \%$ values were directly connected with polymer and crosslinker (\%) [3133]. They were decreased with increasing the amounts of crosslinker and polymer. The reduction was attributed to the fact that the network chains became inflexible at higher crosslinker density and, thus, less amount of water molecules penetrated the hydrogel structure [34]. The equilibrium S\% values were determined to be $490 \%$ for the most swollen hydrogel NaCMC-1 and 102\% for the least swollen hydrogel NaCMC-12.

The variations of $S \%$ values with temperature at $\mathrm{pH}$ 7.0 and $24 \mathrm{~h}$ are presented in Figure 3(b). S\% of hydrogels increased slightly when temperature rose from $10^{\circ} \mathrm{C}$ to $60^{\circ} \mathrm{C}$. This result can be explained by the fact that thermal mobility of polymer chains improved with increasing temperature, so $S \%$ increased based on relaxation of hydrogel structure. NaCMC hydrogels could be suitable for use in wide temperature ranges because they were stable even near $60^{\circ} \mathrm{C}$ [35]. When the amount of polymer in the hydrogels was increased from $3 \%$ to $7 \%$, regular decreasing was observed 

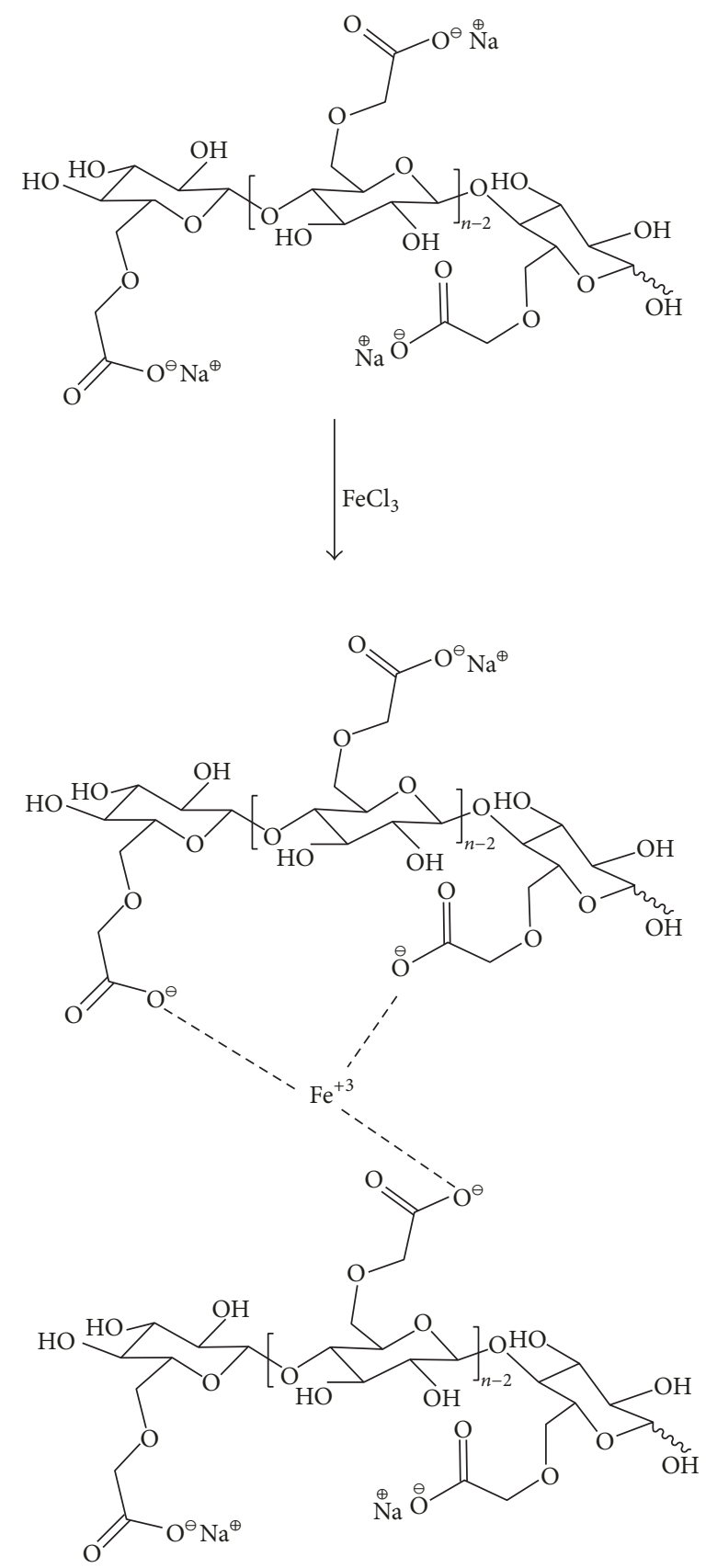

FIGURE 1: The mechanism of ionic crosslinking formation through polymer and crosslinker.

in $S \%$ values. For instance, $S \%$ values were determined to be $600 \%$ for NaCMC-1 hydrogel and $163 \%$ for NaCMC-12 hydrogel at $60^{\circ} \mathrm{C}$. This result can be explained by the fact that the enhancing polymer chains led to increase a great number of crosslinking points in network structure which restrained expansion of hydrogel [31].

In Figure 3(c), the variations of $S \%$ values with $\mathrm{pH}$ are given at $30^{\circ} \mathrm{C}$ and $24 \mathrm{~h} . \mathrm{S} \%$ values at various $\mathrm{pH}$ environments depend upon the available free volume of the expanded polymer matrix, polymer chain relaxation, and availability of ionizable functional groups such as $-\mathrm{COOH}$ able to form hydrogen bonds with water. As seen from Figure 3(c), S\% values of hydrogels increased slightly from $\mathrm{pH} 2.0$ to 7.0 , and then a sharp increment was observed from $\mathrm{pH} 8.0$ to 12.0. For example, $S \%$ values were determined to be $426 \%$ at $\mathrm{pH}$ 2.0 and $998 \%$ at $\mathrm{pH} 12.0$ for NaCMC-1 hydrogel. This result can be explained by the fact that the $\mathrm{pKa}$ of carboxylic acid groups contained in the polymer is about 4.5 [36]. These groups were ionized to the $\mathrm{COO}^{-}$form since the $\mathrm{pH}$ of the environmental solution rose above its $\mathrm{pKa}$ value. The ionized negatively charged pendant groups on the polymer chains caused repulsion leading to swelling. As swelling pressure increased, hydrogel expanded and thereby maximizes the repulsion between the ionized groups. As a result, NaCMC 
TABLE 2: The morphology properties of NaCMC hydrogels.

\begin{tabular}{|c|c|c|c|c|}
\hline Hydrogel & $\begin{array}{l}\text { Average granule density } \\
\text { (number of granule } / \mathrm{cm}^{2} \text { ) }\end{array}$ & $\begin{array}{l}\text { Average granule size } \\
(\mathrm{nm})\end{array}$ & $\begin{array}{l}\text { Average pore size } \\
(\mathrm{nm})\end{array}$ & $\begin{array}{l}\text { Average pore density } \\
\left(\text { number of pore } / \mathrm{cm}^{2} \text { ) }\right.\end{array}$ \\
\hline NaCMC-1 & $9.1 \times 10^{11} \pm 0.2$ & $66.7 \pm 0.9$ & $237.8 \pm 15.4$ & $1.4 \times 10^{9} \pm 0.4$ \\
\hline $\mathrm{NaCMC}-4$ & $9.4 \times 10^{11} \pm 0.2$ & $62.1 \pm 0.9$ & $189.8 \pm 12.2$ & $2.3 \times 10^{9} \pm 0.4$ \\
\hline NaCMC-5 & $9.2 \times 10^{11} \pm 0.4$ & $45.7 \pm 0.8$ & $183.6 \pm 9.2$ & $8.8 \times 10^{9} \pm 0.5$ \\
\hline NaCMC-8 & $10.5 \times 10^{11} \pm 0.4$ & $25.8 \pm 0.5$ & $125.2 \pm 7.2$ & $18.8 \times 10^{9} \pm 0.5$ \\
\hline NaCMC-9 & $19.1 \times 10^{11} \pm 0.5$ & $30.4 \pm 0.2$ & $129.6 \pm 5.7$ & $19.4 \times 10^{9} \pm 0.6$ \\
\hline NaCMC-12 & $21.2 \times 10^{11} \pm 0.5$ & $13.1 \pm 0.3$ & $82.1 \pm 3.2$ & $20.2 \times 10^{9} \pm 0.6$ \\
\hline
\end{tabular}

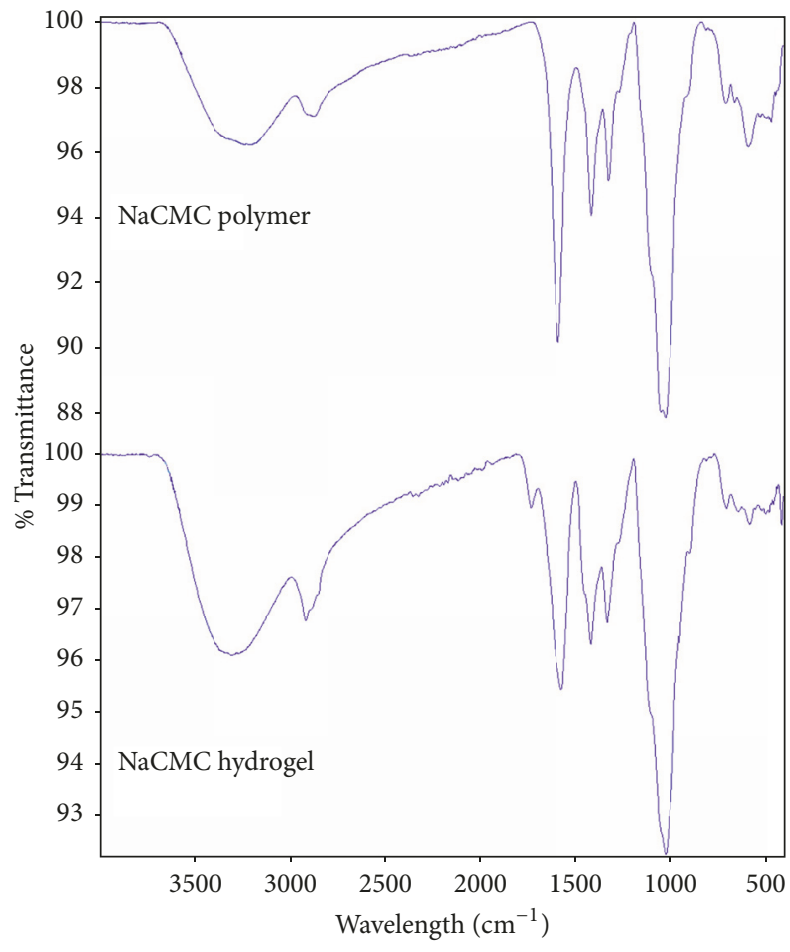

FIGURE 2: ATR-FTIR spectra of polymer and hydrogels.

hydrogels could be evaluated as sensitive to $\mathrm{pH}$ variations $[37,38]$.

3.4. Degradation Behaviors. If any hydrogel will be used for long-term application, the stability of its structure is very important. In some cases, the cross-linkage in the network may break down and the polymer chains dissolve into the medium. Therefore, it is essential to know the degradation behaviors of the hydrogel samples [39, 40]. Degradation behaviors of the hydrogels at $\mathrm{pH} 7.0$ and $30^{\circ} \mathrm{C}$ are presented in Figure 3(d). As could be clearly seen from the figure, crosslinking density decelerated the degradation of the hydrogels [41, 42]. Higher crosslinked hydrogel degraded faster than lower crosslinked hydrogels, since the number of intermolecular bonds improved with increasing crosslinking density. The fastest degradation was observed for NaCMC-1 hydrogel at 30 days. All the hydrogels degraded in approximately 30-36 days. NaCMC hydrogels can be suitable for long-term applications because of their good stabilities.
3.5. SEM/EDX Analysis. SEM analysis was performed to determine morphology properties of the NaCMC hydrogels. The surface and cross-section images of hydrogels are given in Figures 4-7.

The morphological differences between dry and wet states of hydrogels can be clearly observed in Figure 4. The dried surface exhibited smooth and nonporous structure, contrary to the surface of swollen hydrogels which had a granule structure. This situation can be explained by the fact that the ionic crosslinking occurred intensively on the surface. Polymer chains bound to crosslinker from large number of points, so a granulated view appeared on the surface. The surface SEM images of swollen NaCMC-9 hydrogel and swollen NaCMC-12 hydrogels were given in Figure 5.

As seen in Figure 6 the cross-section images of swollen hydrogels, which were completely different from surface images of swollen hydrogels, possessed a spongy structure with pores in different sizes from micro- to nanoscale, so this porosity enabled easy diffusion and absorption of water into the structure $[43,44]$.

Other detailed photographs belonging to swollen NaCMC-9 and NaCMC-12 hydrogels are presented in Figure 7. The morphologic difference of surface and crosssection images was clearly seen from this Figure. As a result, the hydrogel beads can be defined as shelled structure.

Average granule density, average pore density, average granule size, and average pore size were directly determined from SEM images. The results are given in Table 2.

In general, the granule and pore sizes of all hydrogels were mostly in nanosize. Average granule density nearly doubled as the amounts of polymer and crosslinker were increased. The ionic crosslinking bond points were clearly detected from these images. The pore sizes of the hydrogels varied from $82.1 \pm 3.2 \mathrm{~nm}$ to $237.8 \pm 15.4 \mathrm{~nm}$. The largest and smallest pore sizes were obtained for $\mathrm{NaCMC}-1$ and NaCMC-12 hydrogels, respectively. While the amount of crosslinker was increased, the pores got smaller. Similar effect was observed from the comparison of $\mathrm{NaCMC}$ hydrogel pairs numbered as (1-4), (5-8), and (9-12). Besides, increasing the amount of polymer in the hydrogels numbered as (1-5-9) and (4-8-12) resulted in a decrease in pore sizes [27]. Average pore density values were compassable with pore sizes. As the pore sizes got smaller, pore densities increased from $1.4 \times$ $10^{9}$ to $20.2 \times 10^{9}$ number of pore in $\mathrm{cm}^{2}$. SEM evaluations were in good agreement with the observed swelling results. The most swollen hydrogel NaCMC-1 had the largest pore, 

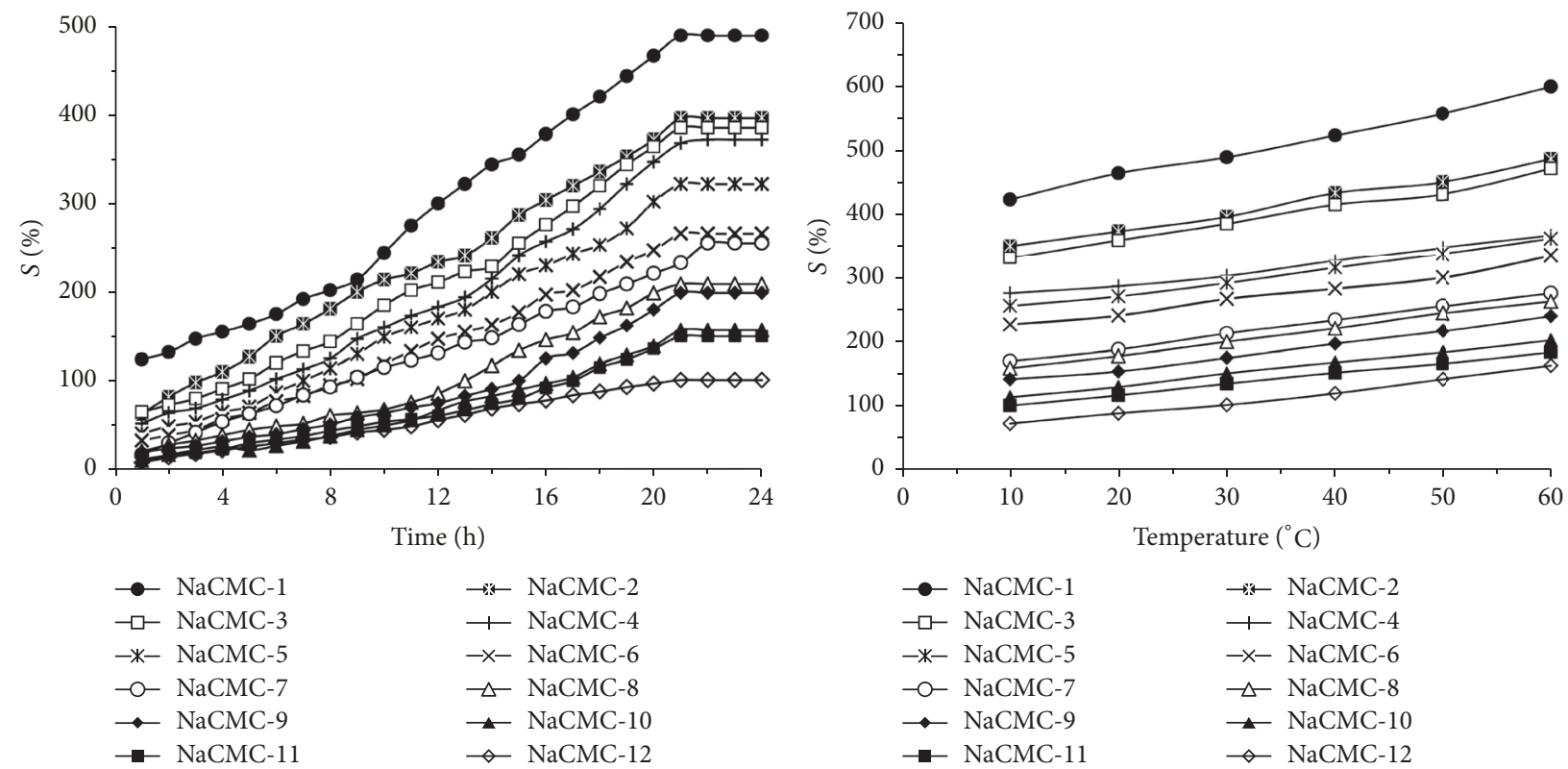

(a)
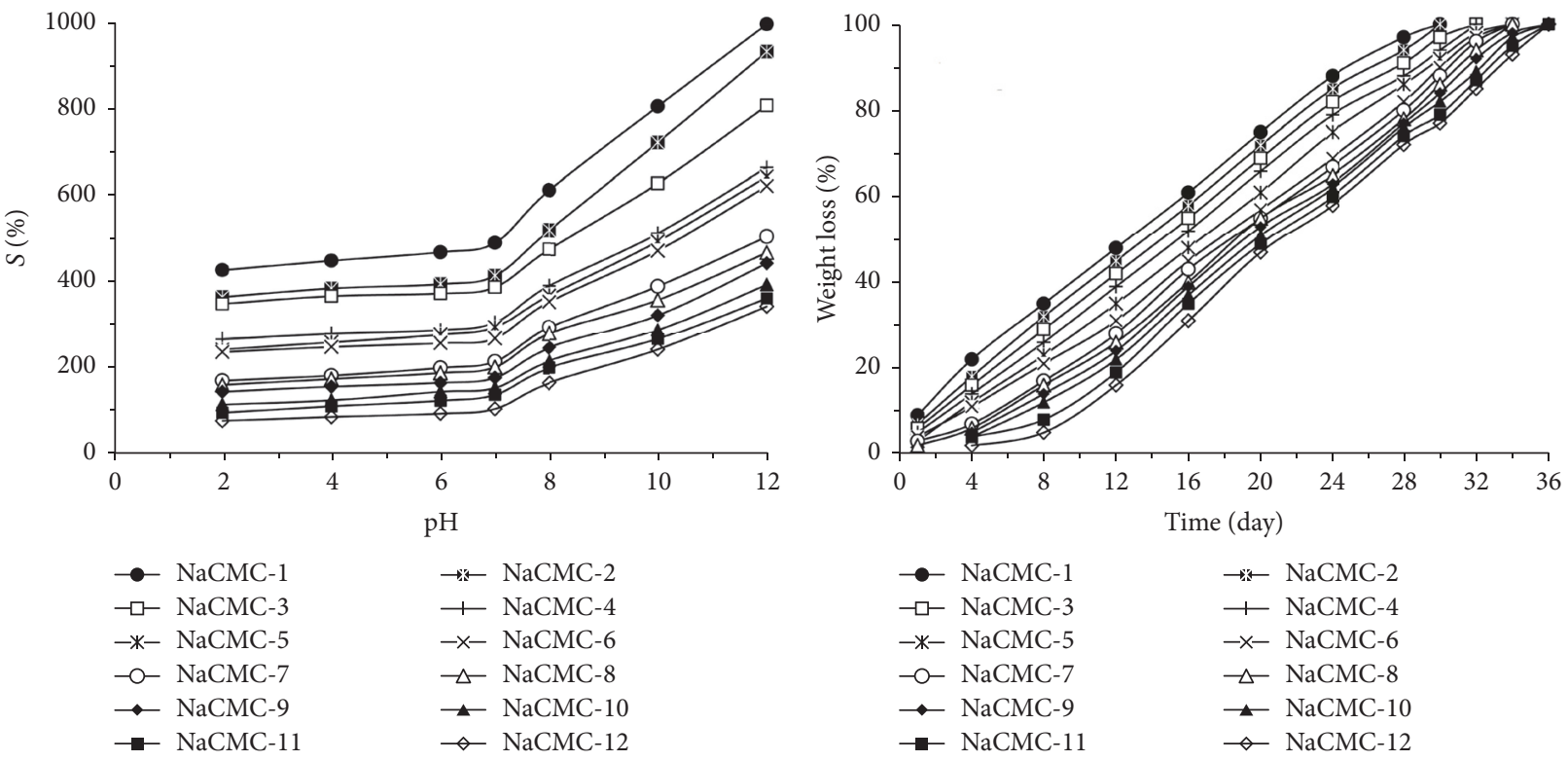

(c)

(d)

Figure 3: (a) The variations of $S \%$ with time, (b) the variations of $S \%$ with temperature, (c) the variations of $S \%$ with $\mathrm{pH}$, and (d) the variations of weight lost $\%$ with day.

whereas the least swollen hydrogel NaCMC-12 had small sizes.

The EDX spectra of NaCMC-5, NaCMC-6, NaCMC-7, and NaCMC-8 hydrogels are presented in Figure 8 . The detected weight and atomic fractions of $\mathrm{Na}$ and Fe elements are given in Table 3. While the amount of $\mathrm{FeCl}_{3}$ increased from $4 \%$ to $10 \%$, the weight fraction of Fe element rose from $5.72 \%$ to $21.96 \%$ in the spectra $[45,46]$. Besides, it could be clearly seen that the peak intensity of $\mathrm{Na}$ element was reduced with increasing $\mathrm{FeCl}_{3}$ concentration. Because the ionic bonding between $\mathrm{Fe}^{3+}$ and polymer chains progressed through the ionized $\mathrm{Na}^{+}$, the weight fraction of $\mathrm{Na}$ element diminished from $44.21 \%$ to $14.96 \%$. It is detected that $\mathrm{Wt} \%$ of Fe increased nearly fourfold, while $\mathrm{Wt} \%$ of $\mathrm{Na}$ decreased 1/4 times. Similar results were obtained for atomic fraction values. From EDX results, it could be concluded that the ionic crosslinking between NaCMC chains was successfully realized.

3.6. AFM Analysis. Three-dimension AFM images of the selected hydrogel samples are shown in Figure 9. In general, the surfaces of hydrogels had nodular structure containing many peaks which have both large and small dimensions. It was clearly seen that the surfaces of hydrogels became smoother 


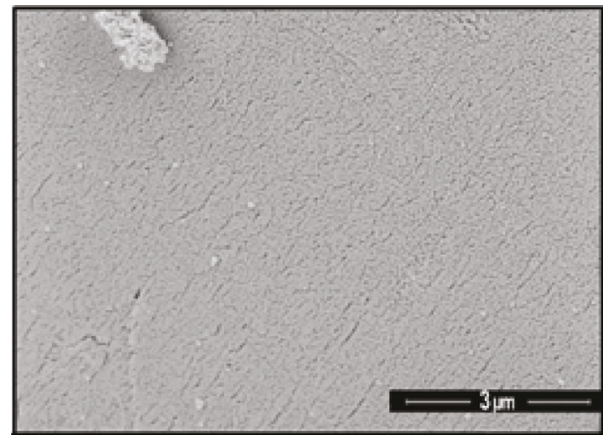

(a)

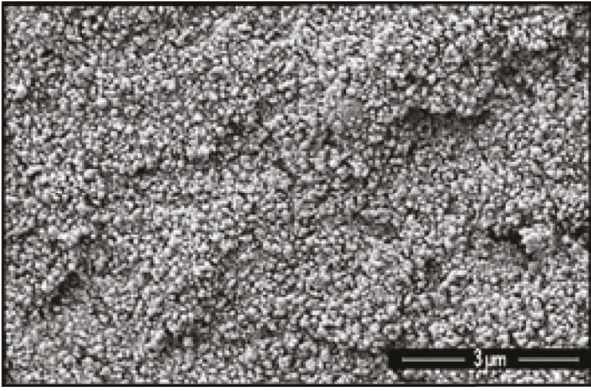

(b)

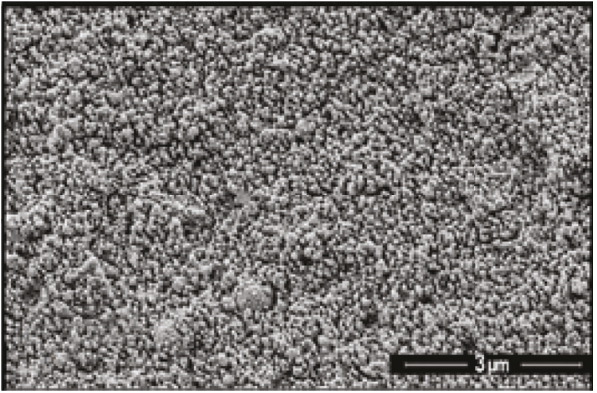

(d)

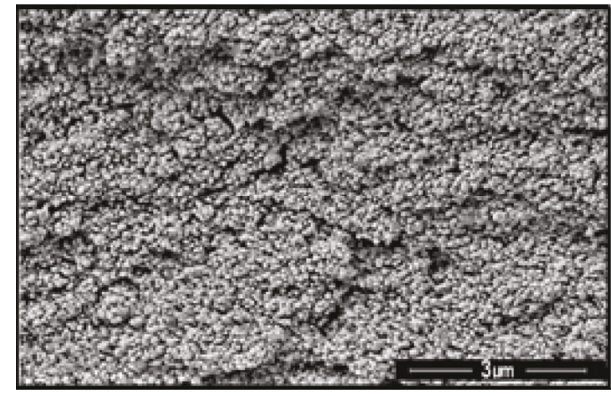

(c)

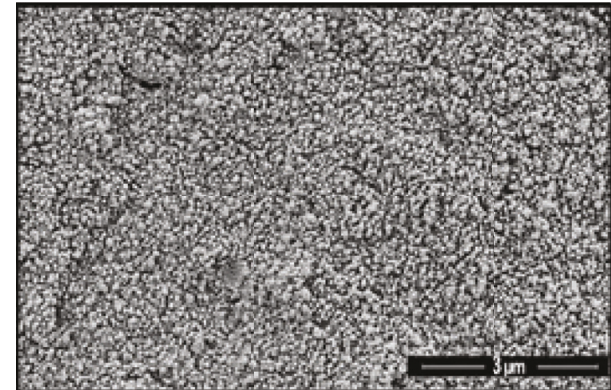

(e)

FIgURE 4: The surface SEM images of $(3 \mu \mathrm{m})$ (a) dried hydrogel, (b) swollen NaCMC-1 hydrogel, (c) swollen NaCMC-4 hydrogel, (d) swollen NaCMC-5 hydrogel, and (e) swollen NaCMC-8 hydrogel.

TABLE 3: The weight and atomic fractions of $\mathrm{NaCMC}$ hydrogels and used $\mathrm{FeCl}_{3}$ (\%) solutions.

\begin{tabular}{lccccc}
\hline Hydrogel & $\mathrm{FeCl}_{3}(\%)$ & $\mathrm{FeK}(\mathrm{Wt} \%)$ & $\mathrm{FeK}(\mathrm{At} \%)$ & $\mathrm{NaK}(\mathrm{Wt} \%)$ & $\mathrm{NaK}(\mathrm{At} \%)$ \\
\hline NaCMC-5 & 4 & $5.7 \pm 0.3$ & $4.3 \pm 0.2$ & $44.2 \pm 2.1$ & $55.3 \pm 2.1$ \\
NaCMC-6 & 6 & $12.5 \pm 0.9$ & $11.4 \pm 0.7$ & $32.7 \pm 1.7$ & $45.1 \pm 1.8$ \\
NaCMC-7 & 8 & $18.3 \pm 1.1$ & $15.5 \pm 1.1$ & $30.8 \pm 1.6$ & $43.2 \pm 1.6$ \\
NaCMC-8 & 10 & $21.9 \pm 1.4$ & $20.8 \pm 1.2$ & $14.9 \pm 1.1$ & $24.0 \pm 1.3$ \\
\hline
\end{tabular}

with increasing crosslinker and polymer concentrations. This observation was compatible with SEM analysis. The quantitative analysis of the surface roughness was measured through AFM. $R_{\mathrm{a}}$ and $R_{\mathrm{ms}}$ values were summarized in Table 4 . The maximum roughness parameters were obtained for $\mathrm{NaCMC}$ 1 hydrogel. By comparison of NaCMC-1 and NaCMC-4 hydrogels, it was seen that $R_{\mathrm{a}}$ values decreased from $160.0 \pm$ $1.1 \mathrm{~nm}$ to $108.1 \pm 1.2 \mathrm{~nm}$. $R_{\mathrm{a}}$ values were obtained as $108.1 \pm 1.2$, $60.0 \pm 1.5 \mathrm{~nm}$, and $15.7 \pm 1.9 \mathrm{~nm}$ for NaCMC-4, NaCMC-8, and NaCMC-12 hydrogels, respectively. Similar results were obtained for $R_{\mathrm{ms}}$ parameter. These results showed that the surface roughness parameters would be reduced when the crosslinking density was increased; thereby the surface of hydrogels became smooth. The results are compatible with the literature $[47,48]$.

\section{Conclusion}

In summary, nanoporous NaCMC hydrogel beads were successfully synthesized by ionic crosslinking method. 


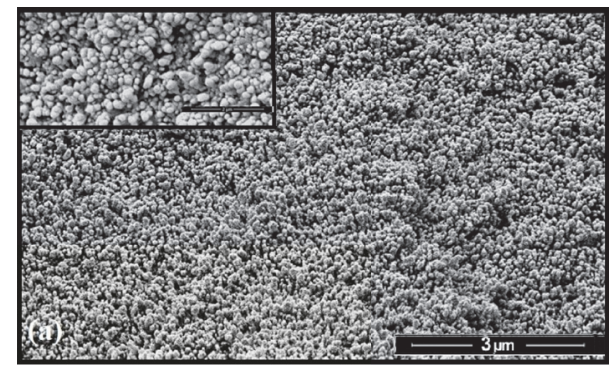

(a)

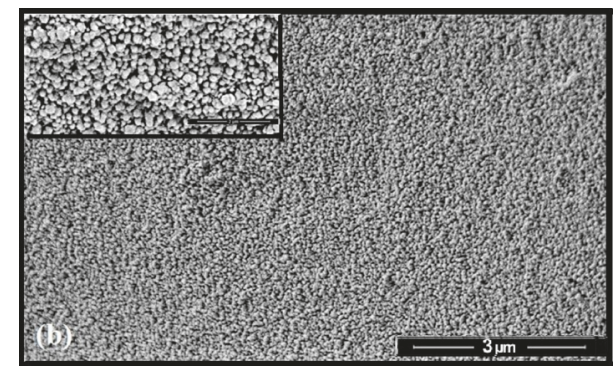

(b)

FIGURE 5: The surface SEM images of ( $3 \mu \mathrm{m}$, inset figure $2 \mu \mathrm{m}$ ) (a) swollen NaCMC-9 hydrogel and (b) swollen NaCMC-12 hydrogel.

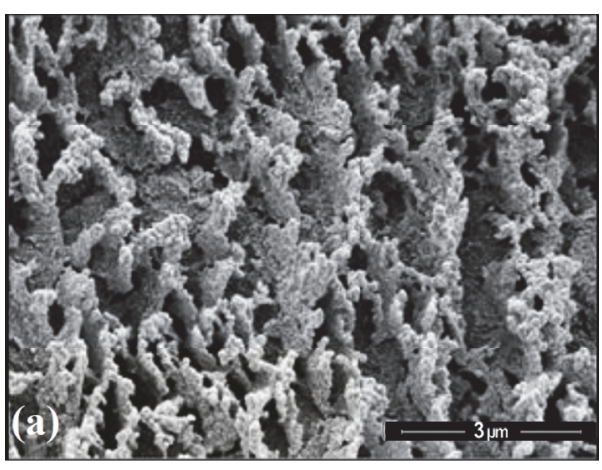

(a)

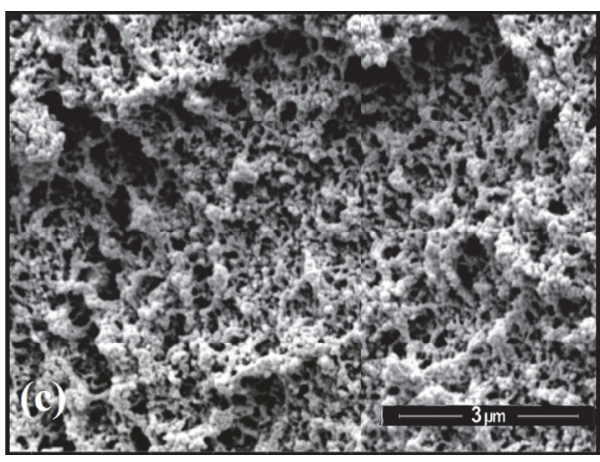

(c)

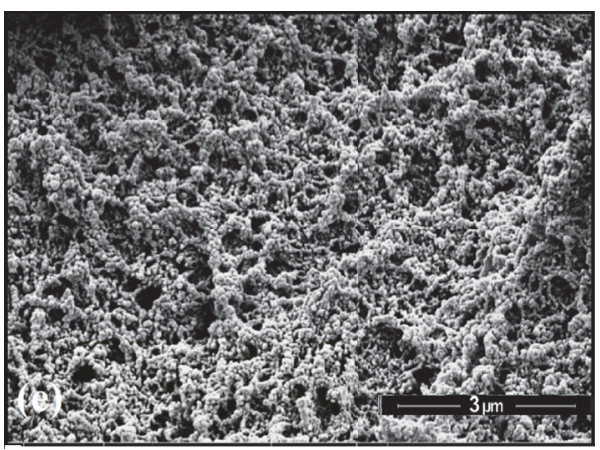

(e)

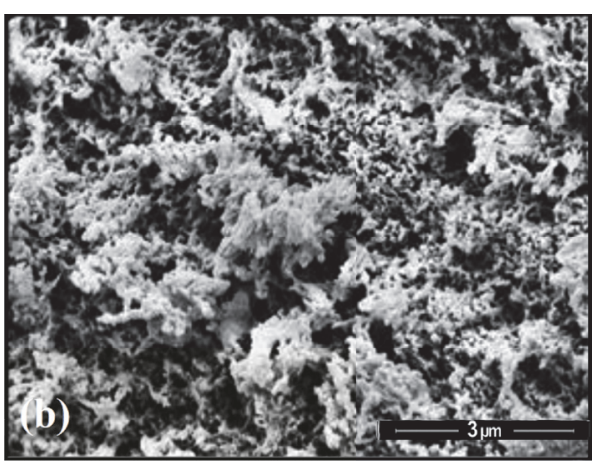

(b)

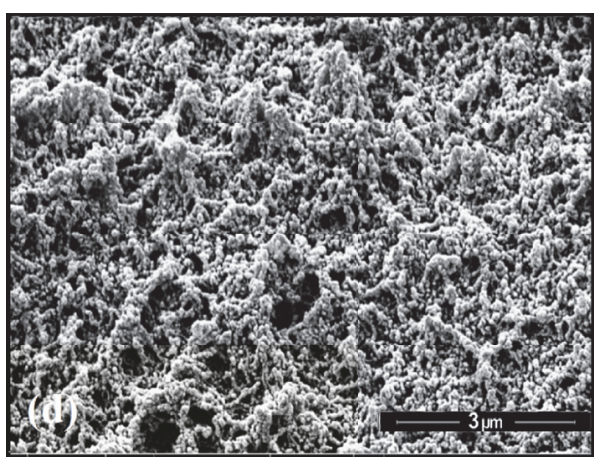

(d)

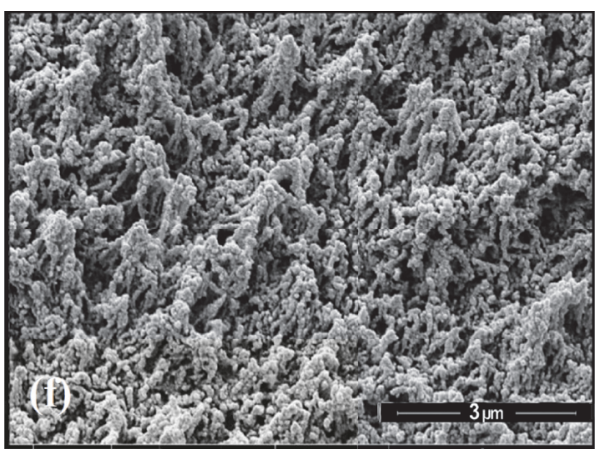

(f)

Figure 6: The cross-section SEM images of $(3 \mu \mathrm{m})$ (a) swollen NaCMC-1 hydrogel, (b) swollen NaCMC-4 hydrogel, (c) swollen NaCMC-5 hydrogel, (d) swollen NaCMC-8 hydrogel, (e) swollen NaCMC-9 hydrogel, and (f) swollen NaCMC-12 hydrogel. 


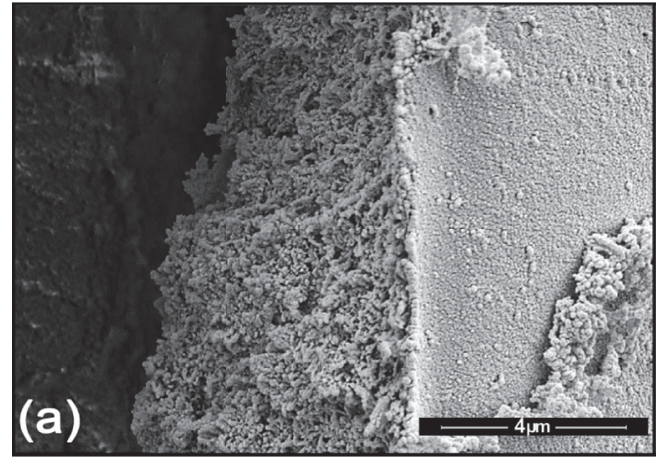

(a)

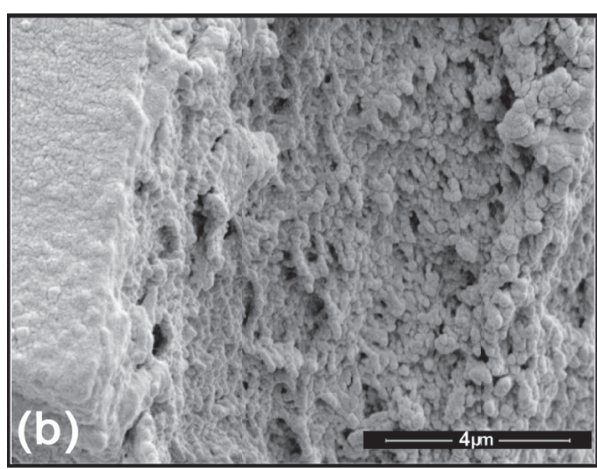

(b)

FIGURE 7: The cross-section SEM images of $(4 \mu \mathrm{m})$ (a) swollen NaCMC-9 hydrogel and (b) swollen NaCMC-12 hydrogel.

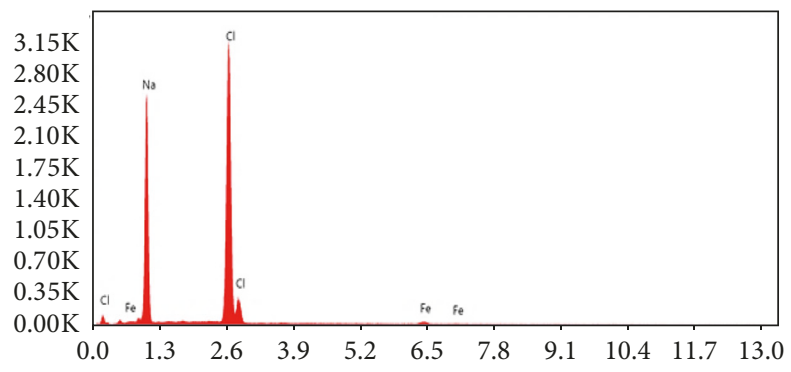

Lsec: 29.50 Cnts $0.000 \mathrm{keV}$ Det: Octane Pro Det

(a)

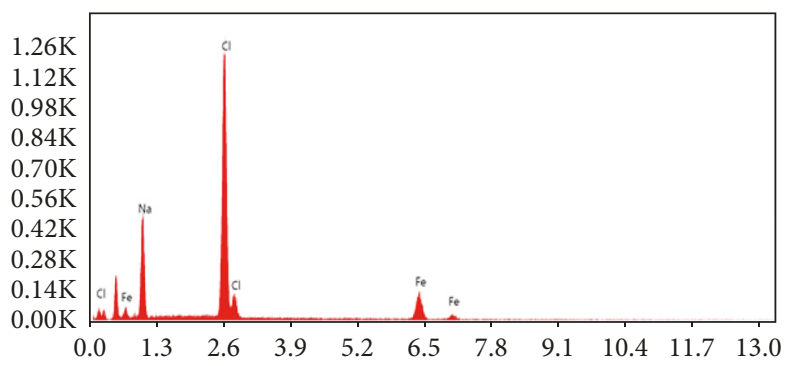

Lsec: 29.60 Cnts $0.000 \mathrm{keV}$ Det: Octane Pro Det

(c)

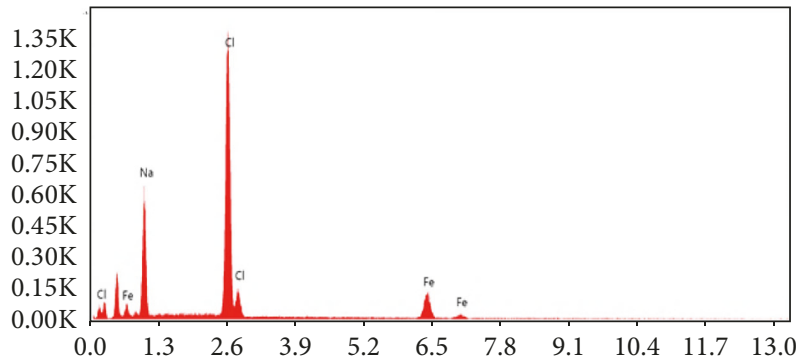

Lsec: 29.60 Cnts $0.000 \mathrm{keV}$ Det: Octane Pro Det

(b)

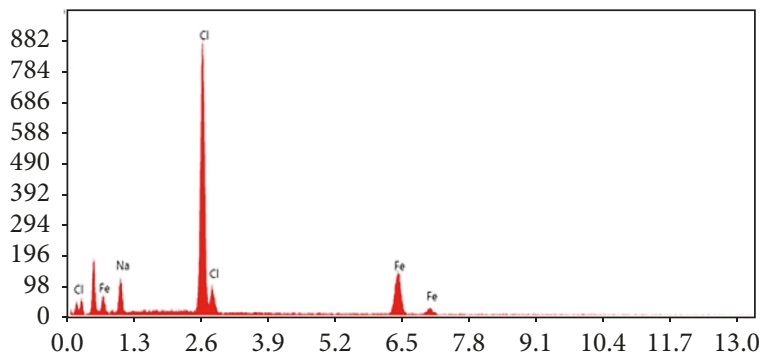

Lsec: 29.60 Cnts $0.000 \mathrm{keV}$ Det: Octane Pro Det

(d)

Figure 8: The EDX spectra of (a) NaCMC-5 hydrogel, (b) NaCMC-6 hydrogel, (c) NaCMC-7 hydrogel, and (d) NaCMC-8 hydrogel.

TABLE 4: The surface roughness parameters of NaCMC hydrogels.

\begin{tabular}{lcc}
\hline Hydrogel & $R_{\mathrm{ms}}(\mathrm{nm})$ & $R_{\mathrm{a}}(\mathrm{nm})$ \\
\hline NaCMC-1 & $200.0 \pm 3.3$ & $160.0 \pm 1.1$ \\
NaCMC-4 & $137.1 \pm 2.2$ & $108.1 \pm 1.2$ \\
NaCMC-5 & $130.0 \pm 2.4$ & $80.0 \pm 1.3$ \\
NaCMC-8 & $76.6 \pm 2.5$ & $60.0 \pm 1.5$ \\
NaCMC-9 & $60.0 \pm 2.3$ & $50.0 \pm 1.7$ \\
NaCMC-12 & $20.3 \pm 2.2$ & $15.7 \pm 1.9$ \\
\hline
\end{tabular}

The characterization was conducted with Attenuated Total Reflectance-Fourier Transform Infrared (ATR-FTIR), Scanning Electron Microscope/Energy Dispersive X-ray Analysis (SEM/EDX), Atomic Force Microscopy (AFM), gel content, and swelling and degradation tests. In swelling and degradation tests, the synthesized nanoporous hydrogels were determined to be $\mathrm{pH}$ sensitive hydrogel and a suitable material for long-term use. The nanomaterials formed a porous structure sensitive to changes in the concentration of polymer and crosslinker. The average pore and granule size of the material decreased with increasing the amounts of $\mathrm{NaCMC}$ and $\mathrm{FeCl}_{3}$. The minimum granule and pore sizes were found at $13.1 \pm 0.3 \mathrm{~nm}$ and $82.1 \pm 3.2 \mathrm{~nm}$ for the least swollen NaCMC-12 hydrogel. AFM analysis showed that the increasing of crosslinking caused a smooth structure on the hydrogel surface. The maximum and minimum average surface roughness $\left(R_{\mathrm{a}}\right)$ parameters were found to be $160.0 \pm 1.1 \mathrm{~nm}$ and $15.7 \pm 1.9 \mathrm{~nm}$ for NaCMC- 1 and NaCMC-12 hydrogels, respectively. These results indicated that it is possible to control the pore sizes, surface morphology, and swelling/degradation capacity of the hydrogels 


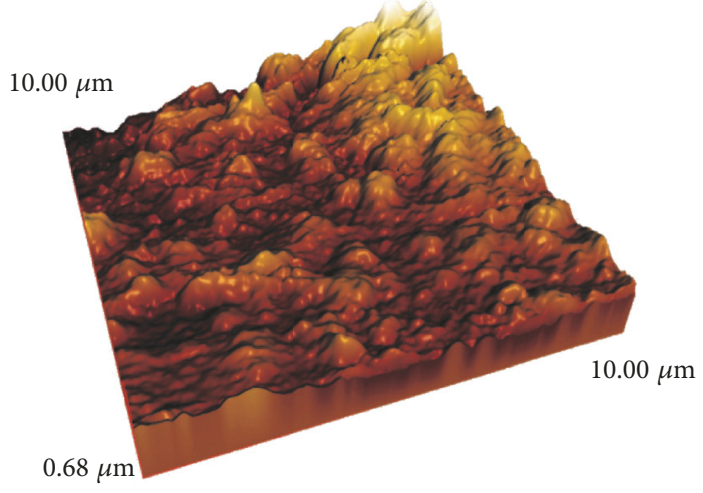

0.0

(a)

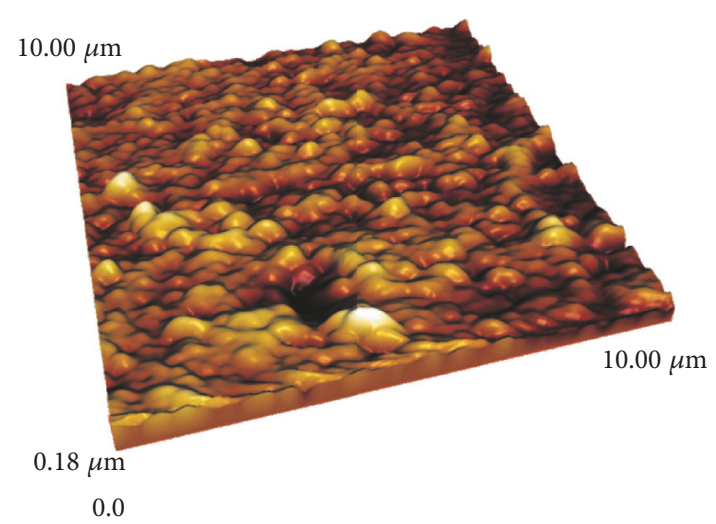

(c)

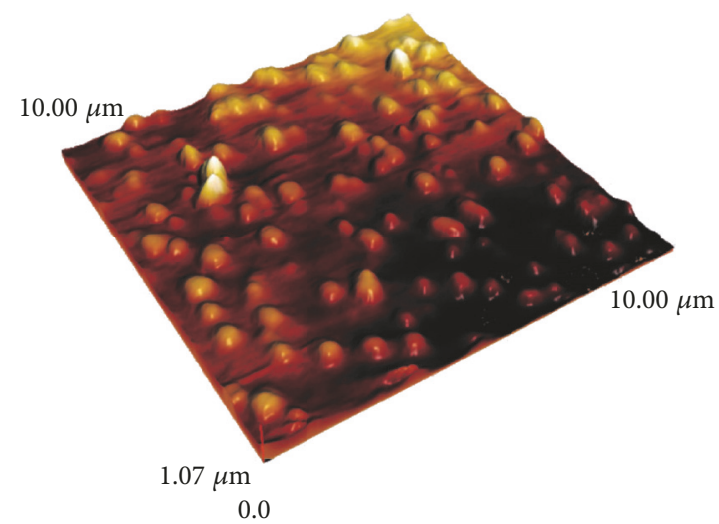

(e)

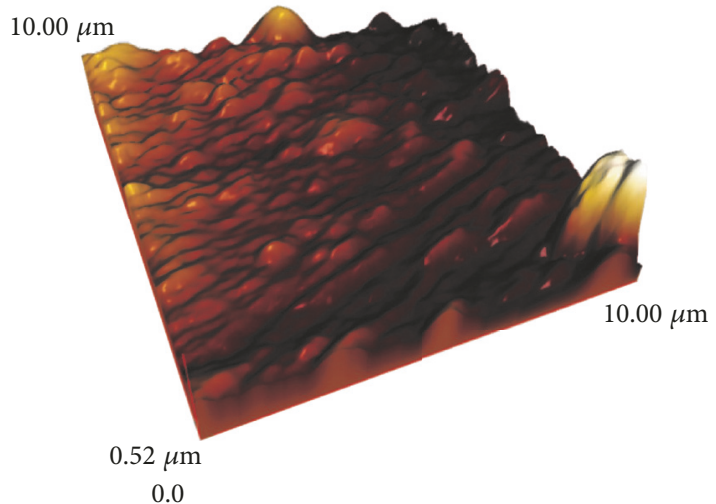

(b)

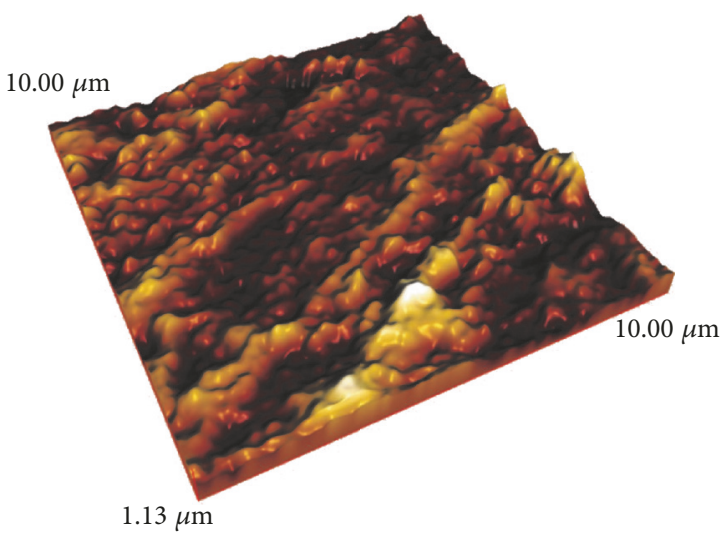

(d)

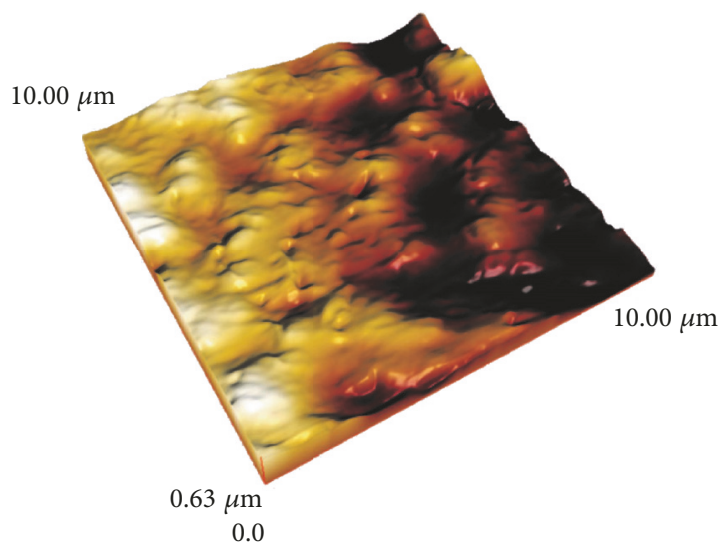

(f)

Figure 9: The AFM images of (a) NaCMC-1 hydrogel, (b) NaCMC-4 hydrogel, (c) NaCMC-5 hydrogel, (d) NaCMC-8 hydrogel, (e) NaCMC-9 hydrogel, and (f) NaCMC-12 hydrogel.

by changing $\mathrm{NaCMC}$ and $\mathrm{FeCl}_{3}$ concentrations. In these terms, hydrogels presented properties as porosities, suitable morphologies, swelling degree or degradation rates, and good stability which make them suitable for application as biomaterials.

\section{Conflicts of Interest}

The authors declare that they have no conflicts of interest.

\section{Acknowledgments}

This work was financially supported by the Scientific Research Projects Coordination Unit of Gazi University (Grant no. 05/2015-08).

\section{References}

[1] J. Kuang, K. Y. Yuk, and K. M. Huh, "Polysaccharide-based superporous hydrogels with fast swelling and superabsorbent 
properties," Carbohydrate Polymers, vol. 83, no. 1, pp. 284-290, 2010.

[2] Y. Zheng, S. Hua, and A. Wang, "Adsorption behavior of $\mathrm{Cu} 2+$ from aqueous solutions onto starch-g-poly (acrylic acid)/ sodium humate hydrogels," Desalination, vol. 263, no. 1-3, pp. 170-175, 2010.

[3] A. S. Hoffman, "Hydrogels for biomedical applications," Advanced Drug Delivery Reviews, vol. 54, no. 1, pp. 3-12, 2002.

[4] M. Pulat and D. Asil, "Fluconazole release through Semiinterpenetrating polymer network hydrogels based on chitosan, acrylic acid, and citraconic acid," Journal of Applied Polymer Science, vol. 113, no. 4, pp. 2613-2619, 2009.

[5] M. Pulat and M. Çetin, "Pantoprazole-Na release from poly(acrylamide-co-crotonic acid) and poly(acrylic acid-cocrotonic acid) hydrogels," Journal of Bioactive and Compatible Polymers, vol. 23, no. 4, pp. 305-318, 2008.

[6] G. Aykut, V. N. Hasirci, and G. Alaeddinoglu, "Immobilization of yeast cells in acrylamide gel matrix," Biomaterials, vol. 9, no. 2, pp. 168-172, 1988.

[7] M. Pulat and G. O. Akalin, "Preparation and characterization of gelatin hydrogel support for immobilization of Candida Rugosa lipase," Artificial Cells, Nanomedicine and Biotechnology, vol. 41, no. 3, pp. 145-151, 2013.

[8] C. Demitri, F. Scalera, M. Madaghiele, A. Sannino, and A. Maffezzoli, "Potential of cellulose-based superabsorbent hydrogels as water reservoir in agriculture," International Journal of Polymer Science, vol. 2013, Article ID 435073, 6 pages, 2013.

[9] A. Raafat, M. Eid, and M. B. El-Arnaouty, "Radiation synthesis of superabsorbent CMC based hydrogels for agriculture applications," Nuclear Instruments and Methods in Physics Research Section B: Beam Interactions with Materials and Atoms, vol. 283, pp. 71-76, 2012.

[10] M. D. Blanco, O. García, R. M. Trigo, J. M. Teijón, and I. Katime, "5-Fluorouracil release from copolymeric hydrogels of itaconic acid monoester: I. Acrylamide-co-monomethyl itaconate," Biomaterials, vol. 17, no. 11, pp. 1061-1067, 1996.

[11] A. Salerno, R. Borzacchiello, and P. A. Netti, "Pore structure and swelling behavior of porous hydrogels prepared via a thermal reverse-casting technique," Journal of Applied Polymer Science, vol. 122, no. 6, pp. 3651-3660, 2011.

[12] N. Annabi, J. W. Nichol, X. Zhong et al., "Controlling the porosity and microarchitecture of hydrogels for tissue engineering," Tissue Engineering - Part B: Reviews, vol. 16, no. 4, pp. 371-383, 2010.

[13] G. R. Bardajee, A. Pourjavadi, and R. Soleyman, "Novel nanoporous hydrogel as a carrier matrix for oral delivery of tetracycline hydrochloride," Colloids and Surfaces A: Physicochemical and Engineering Aspects, vol. 392, no. 1, pp. 16-24, 2011.

[14] S. Riyajan and J. Nuim, "Interaction of green polymer blend of modified sodium alginate and carboxylmethyl cellulose encapsulation of turmeric extract," International Journal of Polymer Science, vol. 2013, Article ID 364253, 10 pages, 2013.

[15] E. Bulut and O. Sanli, "Novel ionically crosslinked acrylamidegrafted poly(vinyl alcohol)/sodium alginate/sodium carboxymethyl cellulose $\mathrm{pH}$-sensitive microspheres for delivery of Alzheimer's drug donepezil hydrochloride: Preparation and optimization of release conditions," Artificial Cells, Nanomedicine and Biotechnology, vol. 44, no. 2, pp. 431-442, 2016.

[16] R. Barbucci, A. Magnani, and M. Consumi, "Swelling behavior of carboxymethylcellulose hydrogels in relation to crosslinking, pH, and charge density," Macromolecules, vol. 33, no. 20, pp. 7475-7480, 2000.
[17] A. Sannino, C. Demitri, and M. Madaghiele, "Biodegradable cellulose-based hydrogels: design and applications," Materials , vol. 2, no. 2, pp. 353-373, 2009.

[18] R. Reeves, A. Ribeiro, L. Lombardo, R. Boyer, and J. B. Leach, "Synthesis and characterization of carboxymethylcellulosemethacrylate hydrogel cell scaffolds," Polymer, vol. 2, no. 3, pp. 252-264, 2010.

[19] H. T. S. Britton and R. A. Robinson, "Universal buffer solutions and the dissociation constant of veronal," Journal of the Chemical Society, pp. 1456-1462, 1931.

[20] D. Kühbeck, J. Mayr, M. Häring, M. Hofmann, F. Quignard, and D. Díaz Díaz, "Evaluation of the nitroaldol reaction in the presence of metal ion-crosslinked alginates," New Journal of Chemistry, vol. 39, no. 3, pp. 2306-2315, 2015.

[21] K.-S. Chen, Y.-A. Ku, H.-R. Lin et al., "Preparation and characterization of $\mathrm{pH}$ sensitive poly(N-vinyl-2- pyrrolidone/itaconic acid) copolymer hydrogels," Materials Chemistry and Physics, vol. 91, no. 2-3, pp. 484-489, 2005.

[22] M. Pulat, G. O. Akalin, and N. D. Karahan, "Lipase release through semi-interpenetrating polymer network hydrogels based on chitosan, acrylamide, and citraconic acid," Artificial Cells, Nanomedicine and Biotechnology, vol. 42, no. 2, pp. 121127, 2014.

[23] G. Hsiue, J. Guu, and C. Cheng, "Poly(2-hydroxyethyl methacrylate) film as a drug delivery system for pilocarpine," Biomaterials, vol. 22, no. 13, pp. 1763-1769, 2001.

[24] M. Pulat, E. Memiş, and M. Gümüşderelioglu, "Adsorption of bovine serum albumin onto surface-modified polyhydroxyethyl methacrylate beads," Journal of Biomaterials Applications, vol. 17, no. 3, pp. 237-248, 2003.

[25] M. Pulat and H. I. Ozgunduz, "Swelling behavior and morphological properties of semi-IPN hydrogels based on ionic and non-ionic components," Bio-Medical Materials and Engineering, vol. 24, no. 4, pp. 1725-1733, 2014.

[26] A. Vashist, Y. K. Gupta, and S. Ahmad, "Interpenetrating biopolymer network based hydrogels for an effective drug delivery system," Carbohydrate Polymers, vol. 87, no. 2, pp. 14331439, 2012.

[27] R. Vulpe, M. Popa, L. Picton et al., "Crosslinked hydrogels based on biological macromolecules with potential use in skin tissue engineering," International Journal of Biological Macromolecules, vol. 84, pp. 174-181, 2016.

[28] S. Chen, Y. Wu, F. Mi, Y. Lin, L. Yu, and H. Sung, "A novel pHsensitive hydrogel composed of N,O-carboxymethyl chitosan and alginate cross-linked by genipin for protein drug delivery," Journal of Controlled Release, vol. 96, no. 2, pp. 285-300, 2004.

[29] J. M. González-Méijome, A. López-Alemany, J. B. Almeida, and M. A. Parafita, "Surface AFM microscopy of unworn and worn samples of silicone hydrogel contact lenses," Journal of Biomedical Materials Research Part B: Applied Biomaterials, vol. 88, no. 1, pp. 75-82, 2009.

[30] G. R. Bardajee and Z. Hooshyar, "One-pot synthesis of biocompatible superparamagnetic iron oxide nanoparticles/hydrogel based on salep: characterization and drug delivery," Carbohydrate Polymers, vol. 101, no. 1, pp. 741-751, 2014.

[31] B. Y. Swamy and Y.-S. Yun, "In vitro release of metformin from iron (III) cross-linked alginate-carboxymethyl cellulose hydrogel beads," International Journal of Biological Macromolecules, vol. 77, pp. 114-119, 2015.

[32] M. S. Kim, S. J. Park, B. K. Gu, and C.-H. Kim, "Ionically crosslinked alginate-carboxymethyl cellulose beads for the 
delivery of protein therapeutics," Applied Surface Science, vol. 262, pp. 28-33, 2012.

[33] S. Wang, Q. Zhang, B. Tan, L. Liu, and L. Shi, "PH-sensitive poly(vinyl alcohol)/sodium carboxymethylcellulose hydrogel beads for drug delivery," Journal of Macromolecular Science, Part B Physics, vol. 50, no. 12, pp. 2307-2317, 2011.

[34] M. Yadollahi, S. Farhoudian, S. Barkhordari, I. Gholamali, H. Farhadnejad, and H. Motasadizadeh, "Facile synthesis of chitosan/ZnO bio-nanocomposite hydrogel beads as drug delivery systems," International Journal of Biological Macromolecules, vol. 82, pp. 273-278, 2016.

[35] X.-C. Xiao, L.-Y. Chu, W.-M. Chen, and J.-H. Zhu, "Monodispersed thermoresponsive hydrogel microspheres with a volume phase transition driven by hydrogen bonding," Polymer Journal, vol. 46, no. 9, pp. 3199-3209, 2005.

[36] V. K. Thakur and M. K. Thakur, "Handbook of Polymers for Pharmaceutical Technologies," Handbook of Polymers for Pharmaceutical Technologies, vol. 1, pp. 1-529, 2015.

[37] I. Muhamad, L. S. Fen, N. H. Hui, and N. A. Mustapha, "Genipin-cross-linked kappa-carrageenan/carboxymethyl cellulose beads and effects on beta-carotene release," Carbohydrate Polymers, vol. 83, no. 3, pp. 1207-1212, 2011.

[38] J. Zhang, M. Fu, M. Zhang, L. Xu, and Y. Gao, "Synthesis of oxidized glycerol monooleate-chitosan polymer and its hydrogel formation for sustained release of trimetazidine hydrochloride," International Journal of Pharmaceutics, vol. 465, no. 1-2, pp. 3241, 2014.

[39] J. Sheng, Y. Wang, L. Xiong et al., "Injectable doxorubicinloaded hydrogels based on dendron-like $\beta$-cyclodextrin-poly (ethylene glycol) conjugates," Polymer Chemistry, vol. 8, no. 10, pp. 1680-1688, 2017.

[40] R. Silva, R. Singh, B. Sarker et al., "Hybrid hydrogels based on keratin and alginate for tissue engineering," Journal of Materials Chemistry B, vol. 2, no. 33, pp. 5441-5451, 2014.

[41] C. Xiao, H. Li, and Y. Gao, "Preparation of fast $\mathrm{pH}-$ responsive ferric carboxymethylcellulose/poly(vinyl alcohol) double-network microparticles," Polymer International, vol. 58, no. 1, pp. 112-115, 2009.

[42] G. Rassu, A. Salis, E. P. Porcu, P. Giunchedi, M. Roldo, and E. Gavini, "Composite chitosan/alginate hydrogel for controlled release of deferoxamine: A system to potentially treat iron dysregulation diseases," Carbohydrate Polymers, vol. 136, pp. 13381347, 2015.

[43] A. Rokhade, S. A. Agnihotri, S. A. Patil, N. Mallikarjuna, P. Kulkarni, and T. M. Aminabhavi, "Semi-interpenetrating polymer network microspheres of gelatin and sodium carboxymethyl cellulose for controlled release of ketorolac tromethamine," Carbohydrate Polymers, vol. 65, no. 3, pp. 243-252, 2006.

[44] A. M. Adel, H. Abou-Youssef, A. A. El-Gendy, and A. M. Nada, "Carboxymethylated cellulose hydrogel; sorption behavior and characterization," Nature and Science, vol. 8, no. 8, pp. 1-13, 2010.

[45] G. R. Bardajee, Z. Hooshyar, M. J. Asli, F. E. Shahidi, and N. Dianatnejad, "Synthesis of a novel supermagnetic iron oxide nanocomposite hydrogel based on graft copolymerization of poly((2-dimethylamino)ethyl methacrylate) onto salep for controlled release of drug," Materials Science and Engineering C: Materials for Biological Applications, vol. 36, no. 1, pp. 277-286, 2014.

[46] C. H. Lai, S. L. Lo, and H. L. Chiang, "Adsorption/desorption properties of copper ions on the surface of iron-coated sand using BET and EDAX analyses," Chemosphere, vol. 41, no. 8, pp. 1249-1255, 2000.
[47] E. Akar, A. Altinişik, and Y. Seki, "Preparation of $\mathrm{pH}$ - and ionicstrength responsive biodegradable fumaric acid crosslinked carboxymethyl cellulose," Carbohydrate Polymers, vol. 90, no. 4, pp. 1634-1641, 2012.

[48] T. Harada, Y. Hirashima, A. Suzuki, M. Goto, N. Kawamura, and M. Tokita, "Synthesis, swelling behavior and surface microstructure of poly(sodium acrylate) gels cross-linked by aluminum ions," European Polymer Journal, vol. 41, no. 9, pp. 21892198,2004 


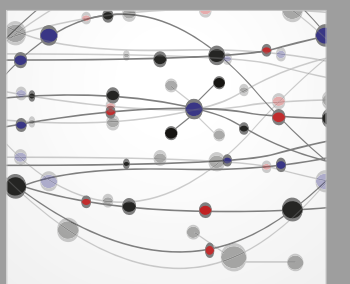

The Scientific World Journal
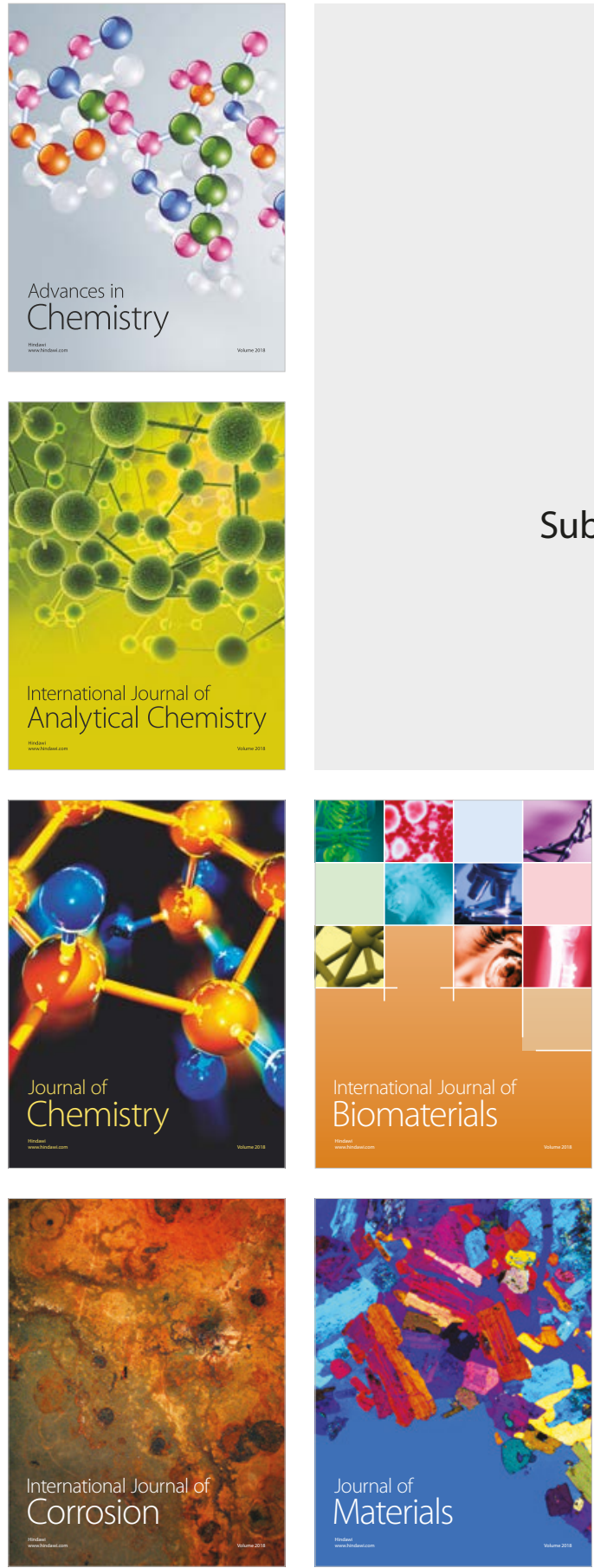

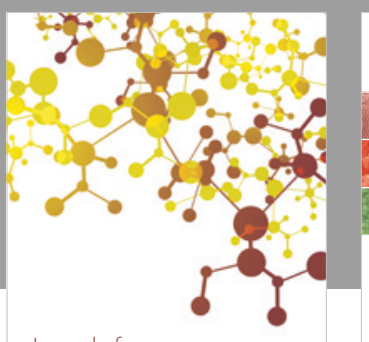

Journal of

Applied Chemistry
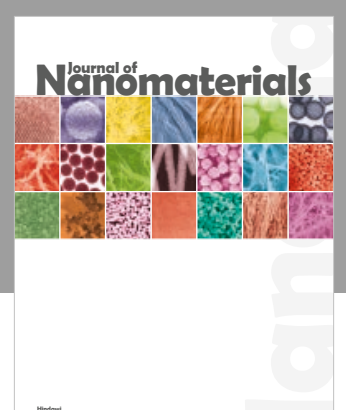

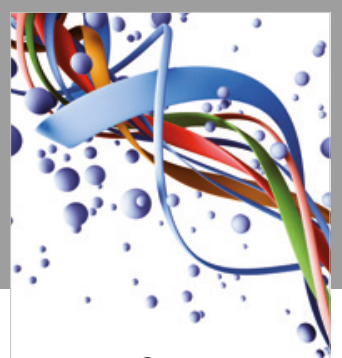

Scientifica

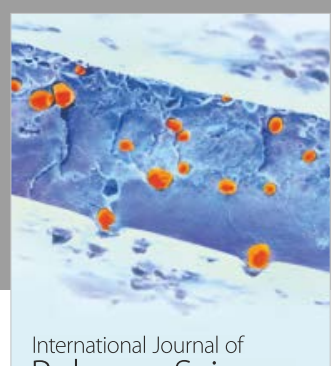

Polymer Science

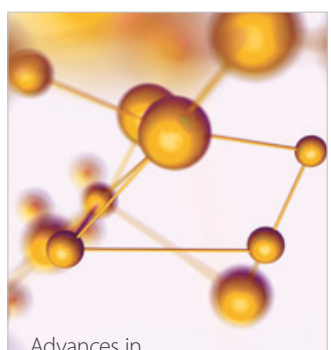

Physical Chemistry
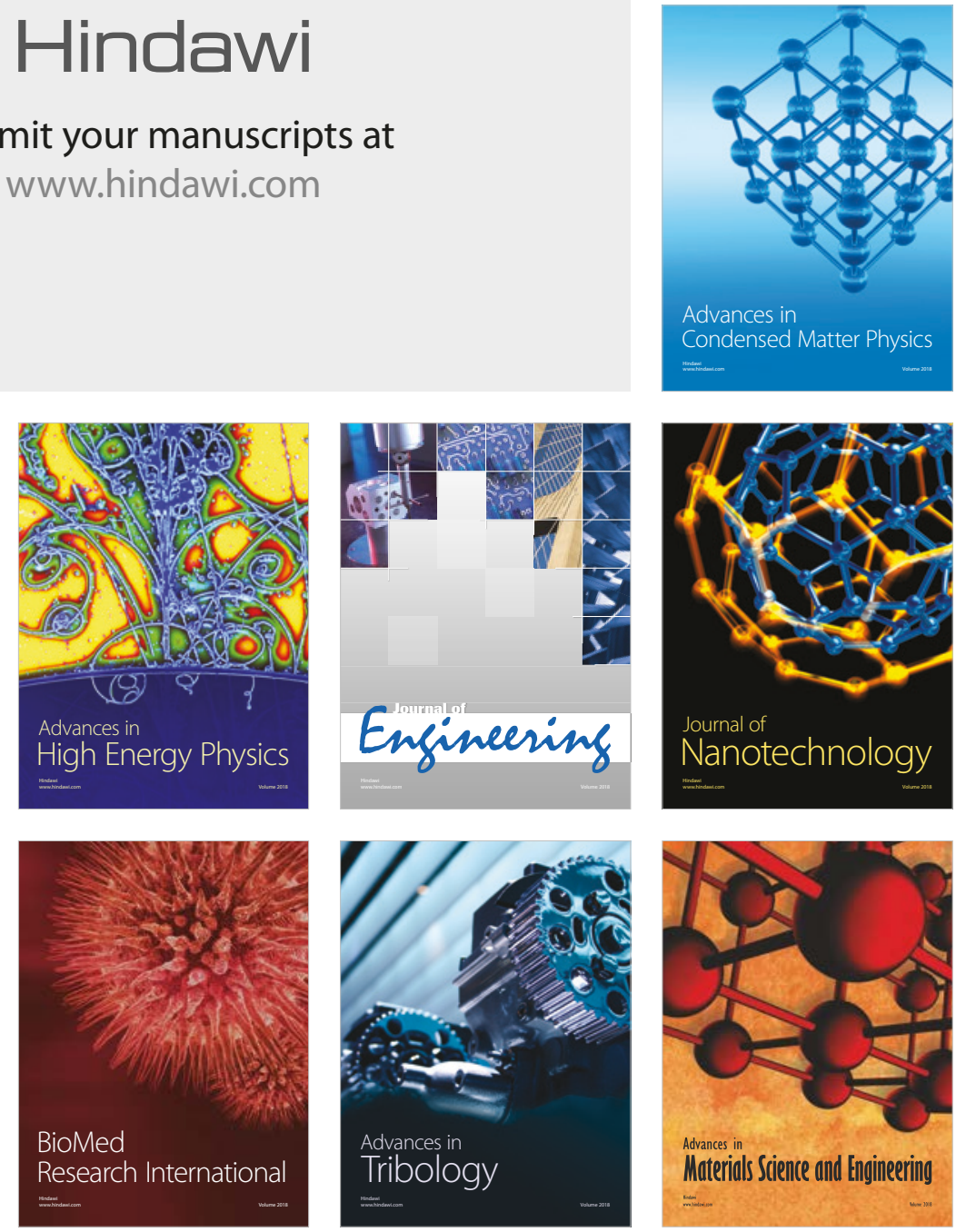